\title{
Cushion plants act as facilitators for soil microarthropods in high alpine Sweden
}

\author{
Peter Luuptáčik ${ }^{1}$ (D) Peter Čuchta ${ }^{2}$ Patrícia Jakšová ${ }^{1}$ - Dana Miklisová ${ }^{3}$ (D) \\ Lubomír Kováćc $^{10}$. Juha M. Alatalo ${ }^{4}$
}

Received: 19 October 2020 / Revised: 16 June 2021 / Accepted: 3 July 2021

(c) The Author(s) 2021

\begin{abstract}
Cushion plants can have positive impacts on plant richness in severe environments and possibly across trophic levels on arthropods, an under-studied topic. This study examined whether soil communities under cushions have higher richness and abundance of soil microarthropods than adjacent non-cushion vegetation, and whether differences in collembolan and mite abundance and species richness between cushions and adjacent vegetation increase with elevation. Paired soil samples were taken under cushions of Silene acaulis along the elevation gradient (1000, 1100, 1200, 1300, $1400 \mathrm{~m}$ a.s.1.), under cushions of Diapensia lapponica on the exposed ridge above the treeline (1000 $\mathrm{m}$ a.s.1.), and under adjacent non-cushion plant vegetation. In total, 5853 individuals of collembolans $(n=1705)$ and mites $(n=4148)$ were obtained from soil samples and identified to order/ species level. S. acaulis cushions had a positive effect on species richness and abundance of collembolans, with richness effects from $1100 \mathrm{~m}$ a.s.l. upwards. Oribatid mite richness and abundance were also higher under cushions compared with adjacent vegetation. Species richness of collembolans and oribatids declined with increasing elevation from $1200 \mathrm{~m}$ a.s.l. Collembolan abundance peaked at mid-elevation (1200 m a.s.1.) under cushions and adjacent vegetation, while oribatid mite abundance peaked at $1300 \mathrm{~m}$ a.s.l. under both vegetation types. $D$. lapponica cushions on the exposed ridge had significant positive effects on species richness, abundance and diversity index of collembolans, and abundance of oribatids. Cushion plants play an important role in supporting the biodiversity of soil fauna in severe alpine environments, with the positive effects of cushion plants increasing with environmental severity.
\end{abstract}

Keywords Alpine tundra - Facilitation - Plant animal interaction · Soil fauna - Soil mites · Springtails

Communicated by P. Ponel.

Juha M. Alatalo

jalatalo@qu.edu.qa

Extended author information available on the last page of the article 


\section{Introduction}

Facilitation is defined as an interaction in which the presence of one species alters the environment in a way that enhances growth, survival, or reproduction of a second, neighboring species (Bronstein 2009). Facilitation effects tend to occur in high-stress environments such as Arctic and alpine ecosystems (Antonsson et al. 2009), and the impact of facilitation tends to increase with environmental stress (Choler et al. 2001; Brooker et al. 2008). However, studies of positive interactions have primarily focused on plant-plant interactions (Callaway and Walker 1997; Choler et al. 2001; Brooker et al. 2008).

The intimate association of various organisms with certain plant species within terrestrial habitats is relatively well-known, in particular for pollinators and phytophagous larvae of insects or phytoparasites. Plant-arthropod interactions in natural alpine habitats have been studied, but mainly for pollinators and benthic or soil surface species (Cardinale et al. 2002; Molina-Montenegro et al. 2006; Sieber et al. 2011; Molenda et al. 2012; Reid and Lortie 2012), with fewer studies on cushion plant-soil arthropod interactions (Coulson et al. 2003; Minor et al. 2016).

Cushion-forming plant species are a common component of communities in alpine environments around the world. Globally, 338 cushion plant species have been recorded in 34 families and 78 genera, mainly in harsh alpine and other cold regions (Hauri and Schröter 1914; Arredondo-Núñez et al. 2009). Cushion plants offer a broad scope of research topics and the ecological evidence to date strongly suggests that cushion plants can be keystone species in their ecosystems (Reid et al. 2010). Predicted changes associated with a changing climate in regions with a high cushion plant abundance make such plants very appropriate for ecological observations and experiments.

Cushion plants act as foundation and nurse species in alpine ecosystems, providing structurally unique microhabitats with more stable environmental conditions, and positively influencing the richness and abundance of other organisms (Badano and Cavieres 2006; Cavieres et al. 2007; Molenda et al. 2012; Bonanomi et al. 2015). Soils under Silene acaulis cushions have been shown to have higher organic carbon (C) content, salinity, total nitrogen $(\mathrm{N})$ and $\mathrm{C} / \mathrm{N}$ ratio, and lower $\mathrm{pH}$ compared with soil under adjacent vegetation (Bonanomi et al. 2015).

In a study in a rocky alpine meadow in British Columbia, Canada, S. acaulis had a higher visitation rate and diversity index of both surface arthropods and pollinators relative to 11 species of non-cushion plants (Reid and Lortie 2012). Higher richness, abundance, and diversity index of ground arthropods and higher richness and abundance, but not diversity, of plants have been observed in cushions of $S$. acaulis in comparison with non-cushion adjacent vegetation in the same area (Molenda et al. 2012). Coulson et al. (2003) found higher soil microarthropod densities under S. acaulis cushions than under five other vascular plants in a high-Arctic vegetation mosaic.

The aims of the present study were to: i) compare soil microarthropod communities inhabiting soil under two cushion plant species, $S$. acaulis along an elevation gradient and Diapensia lapponica on an exposed ridge, with those inhabiting soil under adjacent non-cushion vegetation; and ii) evaluate the effect of elevation gradient and facilitation by cushion plants on microarthropod communities under these two types of vegetation. The hypotheses tested were that: 1) soil communities under cushions of $S$. acaulis and D. lapponica have higher richness and abundance of soil microarthropods (mites, collembolans) than soil communities under adjacent non-cushion vegetation; and 2) a 
facilitation effect, measured as the difference in collembolan and mite abundance and species richness between $S$. acaulis cushions and adjacent vegetation, increases with increasing elevation.

\section{Methods and study area}

\section{Characteristics of the study area}

The study was carried out in northernmost Sweden, at Latnjajaure Field Station (LFS) in the Latnjavagge valley $\left(68^{\circ} 21^{\prime} \mathrm{N}, 18^{\circ} 30^{\prime} \mathrm{E}\right)$. The valley is covered with snow for most of the year, and the climate is classified as sub-Arctic (Polunin 1951; Alatalo and Molau 1995). It has cool summers and relatively mild, snow-rich winters, with mean annual air temperature ranging from -0.76 to $-2.92^{\circ} \mathrm{C}$ between 1993 and 2013 (Alatalo et al. 2017a). Mean annual precipitation since 1993 is $846 \mathrm{~mm}$, but in individual years it has ranged from $607 \mathrm{~mm}$ (1996) to $1091 \mathrm{~mm}$ (2003). July is the warmest month, with mean temperature ranging from $5.9^{\circ} \mathrm{C}$ in 1995 to $13.1^{\circ} \mathrm{C}$ in 2013 (Alatalo et al. 2017a). The vegetation in the valley comprises a wide range of communities that reflect of local soil type and environmental properties, varying from dry to wet and poor and acidic to base-rich (Molau and Alatalo 1998).

\section{Cushion plants}

Silene acaulis (Caryophyllaceae) is a herbaceous cushion plant characteristic of alpine and Arctic tundra habitats in Asia, Europe, Greenland, and North America. It has a disjunct circumpolar distribution in sub-Arctic, Arctic, and alpine locations and a gap in the Siberia region (Junttila and Robberecht 1993; Gussarova et al. 2015). In Europe, the southernmost populations of $S$. acaulis are found in the Alps, Balkans, British Isles, Carpathian Mountains, Cantabrian Mountains, and Pyrenees (Ferrarini et al. 2019b). S. acaulis is widespread in the Latnjavagge valley (1000 $\mathrm{m}$ a.s.1.) to the peak of Latnjačorru mountain (1446 m a.s.1.). As at other sites, the cushion morphology of $S$. acaulis changes with elevation, with the cushions becoming smaller and more compact at higher elevation (Alatalo and Molau 1995; Bonanomi et al. 2015). S. acaulis is a long-lived perennial that forms light-green, moss-like dense dwarf cushions with pink flowers (Morris and Doak 1998). It has high germination rates, and the cushion growth form enables its seedlings to tolerate frost and drought (Milbau et al. 2009). Its small seeds can be dispersed by wind (Gehring and Delph 1999). S. acaulis is polymorphic, with reproductive systems and gender frequencies varying between populations (Alatalo and Molau 1995; Philipp 1997).

Diapensia lapponica (Diapensiaceae) is another cushion-forming and long-lived (up to 400 years) circumpolar Arctic-alpine evergreen perennial species, adapted to the harshest of environments with exposed cold, windswept conditions (Day and Scott 1984; Molau 1997). It forms cushion domes or mats, radiating from a single, stout, woody tap-root, which act as solar heat traps and warm up the soil beneath the cushions (Day and Scott 1984; Molau 1997). The leaves are glabrous, and frost-resistance of the cushion is imparted by extremely dense leaf aggregation (Molau 1997). D. lapponica is common at exposed sites, such as windswept ridge crests, and is indifferent to substrate acidity. In locations with active soil processes, e.g., solifluction, D. lapponica can be found in microhabitats with longer duration of annual snow cover (Molau 1996). It is a slow-growing species, e.g., 
at Latnjajaure the average age at which the plant becomes reproductive is 18 years (Molau 1997). Seedling recruitment of D. lapponica typically takes place during colder years, e.g., in the Latnjavagge valley there is a negative correlation between seedling recruitment and mean annual temperature (Molau 1997). Although D. lapponica is a weak competitor, it can grow in adverse habitats, often on acid soils or low-nutrient soils (Day and Scott 1984; Molau 1997). Where the climate and soil permit, D. lapponica clumps can be invaded and overgrown by competing species (Day and Scott 1984). Research to date on this plant species has focused on recruitment and persistence of D. lapponica seedlings (Sutton et al. 2006), age-related growth and reproduction (Molau 1997), survival and genetic divergence (Ikeda et al. 2008), and pollen limitation of reproduction (Elberling 2001). However, there is a lack of data on the influence of D. lapponica cushions on soil fauna.

\section{Sampling and identification of soil fauna}

In peak summer (25 July) 2013, soil cores (part of a plant cushion with underlying soil) were taken from individual cushions of $S$. acaulis and from adjacent non-cushion vegetation (50-100 cm distance from $S$. acaulis cushions), in a pairwise design along an elevation gradient from the bottom of the Latnjavagge valley (above treeline) along the south-west facing slope to the peak of Latnjačorru mountain (1446 m a.sl.). Sampling was carried out at (m a.s.1.): $1000\left(68^{\circ} 21^{\prime} 30.24^{\prime \prime} \mathrm{N}, 18^{\circ} 29^{\prime} 49.5^{\prime \prime} \mathrm{E}\right), 1100\left(68^{\circ} 21^{\prime} 30.06^{\prime \prime} \mathrm{N}, 18^{\circ} 30^{\prime} 7.08^{\prime \prime} \mathrm{E}\right)$, $1200\left(68^{\circ} 21^{\prime} 30.84^{\prime \prime} \mathrm{N}, 18^{\circ} 30^{\prime} 27.36^{\prime \prime} \mathrm{E}\right), 1300\left(68^{\circ} 21^{\prime} 33.78^{\prime \prime} \mathrm{N}, 18^{\circ} 30^{\prime} 46.57^{\prime \prime} \mathrm{E}\right)$, and 1400 $\left(68^{\circ} 21^{\prime} 45.80^{\prime \prime} \mathrm{N}, 18^{\circ} 31^{\prime} 13.27^{\prime \prime E}\right)$, along the same elevation transect as in a previous study on the facilitation effect of $S$. acaulis on plants (Antonsson et al. 2009). In total, 50 samples were taken (10 at each elevation, 5 samples under each vegetation type).

In addition to the altitudinal gradient study of S. acaulis cushions, on 27 July 2013, 14 soil cores were taken from cushions of D. lapponica and 14 from adjacent non-cushion vegetation in a pairwise design along a ridge at $1000 \mathrm{~m}$ a.s.1. $\left(68^{\circ} 21^{\prime} 23,7^{\prime \prime} \mathrm{N}, 18^{\circ} 29^{\prime}\right.$ 41.16"E) in the Latnjavagge valley (Molau 1996). Photo documentation of the vegetation along the elevation gradient and the exposed ridge is provided in supplementary electronic materials to this paper (Figs. S1-S6).

All the samples were sampled by metal corer $3.6 \mathrm{~cm}$ in diameter $\left(10 \mathrm{~cm}^{2}\right.$ in area) and to a maximum depth of 6-12 cm (depending on soil depth) (Figs. S7-S8). The samples were stored in plastic bags in coolboxes until extraction of soil fauna, which was performed within five days of field sampling using a modified high-gradient extraction apparatus of Tullgren type (self-constructed after Crossley and Blair 1991) applied over seven days.

Collembolans and mites were sorted under a binocular stereomicroscope (Olympus SZ61) and identified under a phase-contrast microscope (Leica DM2500). Collembolans were identified to species level using basic taxonomic keys (Zimdars and Dunger 1994; Fjellberg 1998, 2007; Bretfeld 1999; Potapov 2001; Thibaud et al. 2004; Janssens and Christiansen 2011). Within mites, oribatids were identified to species level using taxonomic keys (Olszanowski 1996; Walter and Proctor 1999, Chapter 3; Weigmann 2006).

\section{Statistical analyses}

To characterize collembolans and oribatids communities at the sites, abundance (A), dominance (D), and species richness (S) were analyzed as community parameters. The dominance of an individual species was expressed as $\mathrm{D}=\mathrm{N}_{\mathrm{i}} / \mathrm{N} \times 100(\%)$, where $\mathrm{N}_{\mathrm{i}}=$ total 
number of individuals of species $i$ and $\mathrm{N}=$ total number of individuals at each site. Diversity and evenness indices were calculated, namely Shannon diversity index $\left(\mathrm{H}^{\prime}\right)$ and Pielou evenness index $\left(\mathbf{J}^{\prime}\right)$, to document the character of the microarthropod communities. Species dominance rank curves with a comparison of trend lines between $S$. acaulis cushions and adjacent vegetation along the elevation gradient were constructed, to assess the differences in structure of soil microarthropod communities (MS Excel 2016). The significance of differences between the trends of the rank dominance curves for the cushions and adjacent vegetation was analyzed. Probability (p) values for differences in the intercepts and in slopes between the regression lines were calculated with ANCOVA (Lowry 2021).

Repeated-measure ANOVA was used to test the significance of abundance variance of soil microarthropods between vegetation types along the elevation gradient. When the data were not normally distributed, Box-Cox transformation was applied. Species of collembolans with more than 100 specimens and species of oribatids with more than 50 specimens in the total material were tested to check for significant differences in ecological parameters between $S$. acaulis cushions and adjacent vegetation along the elevation gradient. The Wilcoxon Matched Pairs Test was used to confirm significant differences between $S$. acaulis cushions and adjacent vegetation for mean abundance, species richness and diversity indices of collembolans and oribatids, and mean abundance of dominant collembolans and oribatids species, for every elevation separately.

Significance of variance in mean abundance of all Acari groups and collembolans, species richness of collembolans and oribatids, and mean abundance of dominant collembolan and oribatid mite species (species with more than 15 specimens in total material) between D. lapponica and adjacent vegetation was tested with the Mann-Whitney Test. All tests were performed using Statistica for Windows, version 12 (2013).

Non-metric multidimensional scaling (NMDS) ordination was used to display patterns of soil microarthropod distribution under $S$. acaulis cushions and adjacent vegetation. A two-dimensional solution was generated without data transformation in the autopilot mode, with the slow and thorough option and Sørensen (Bray-Curtis) distance (appropriate for community data). NMDS was performed using PC-ORD version 7.2 (McCune and Mefford 2016), using a data matrix of the abundance of the selected collembolan and oribatid species (collembolans with more than 100 specimens and oribatids with more than 50 specimens in the total material), calculated for all three vegetation types and elevation.

\section{Results}

\section{Comparison of Silene acaulis and adjacent vegetation along an elevation gradient}

In total, 3807 soil mites and 1392 collembolans were recorded along the elevation gradient, in association with $S$. acaulis cushions and adjacent vegetation. Within the mites, oribatids (2835 individuals), Prostigmata (745 individuals), and Gamasina (193 individuals) were the most numerous groups. Astigmatina represented only a negligible proportion of the total Acari numbers and were therefore excluded from statistical analyses. The recorded collembolan individuals belonged to 10 families, 30 genera and 41 species. The oribatids, the dominant group of soil mites, were identified to species level, with 107 species belonging to 28 families and 52 genera recorded.

Abundances of all Acari and dominant Acari groups were higher under S. acaulis cushions than under adjacent vegetation at all elevations, but only the total for all Acari 


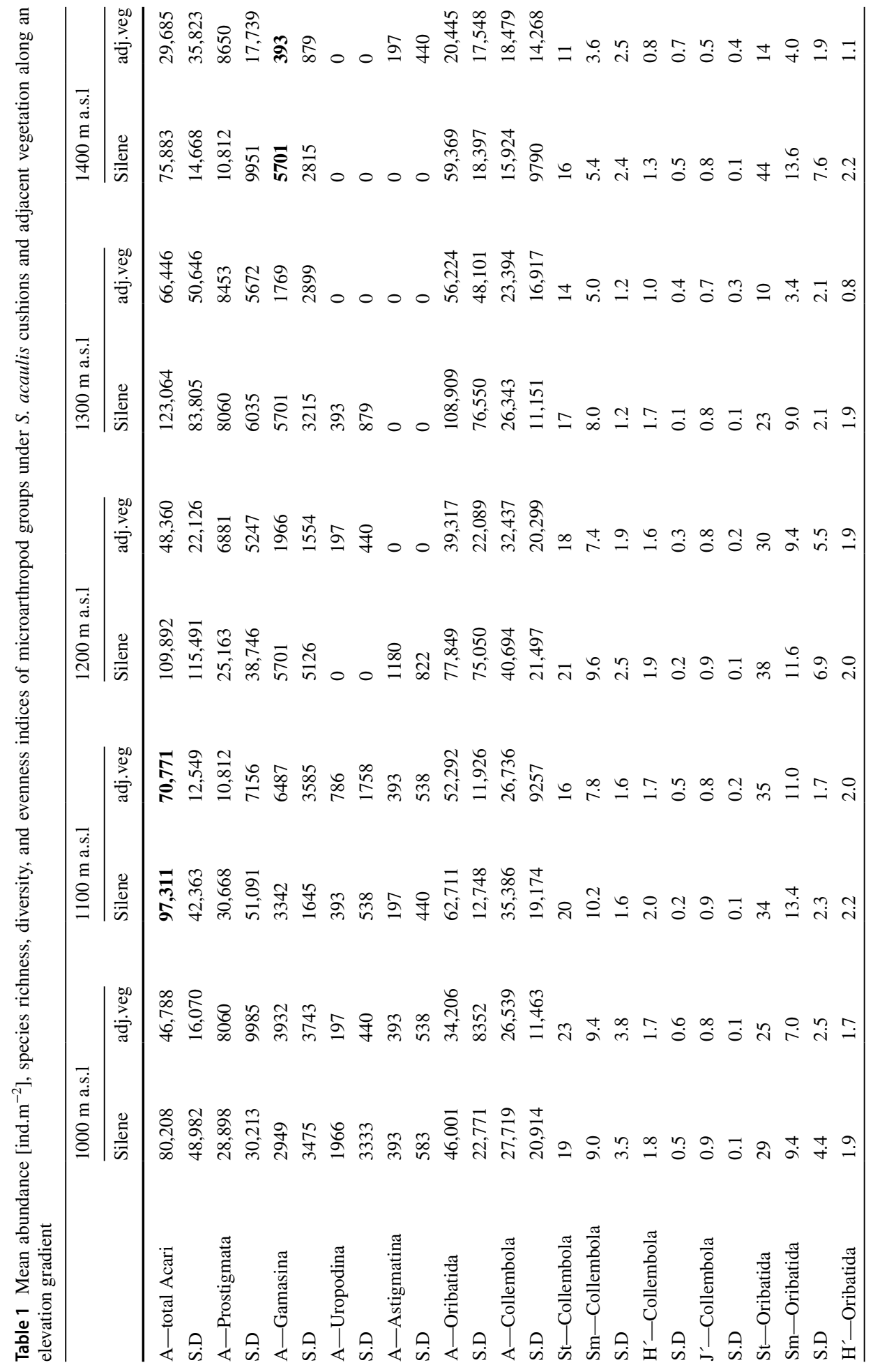




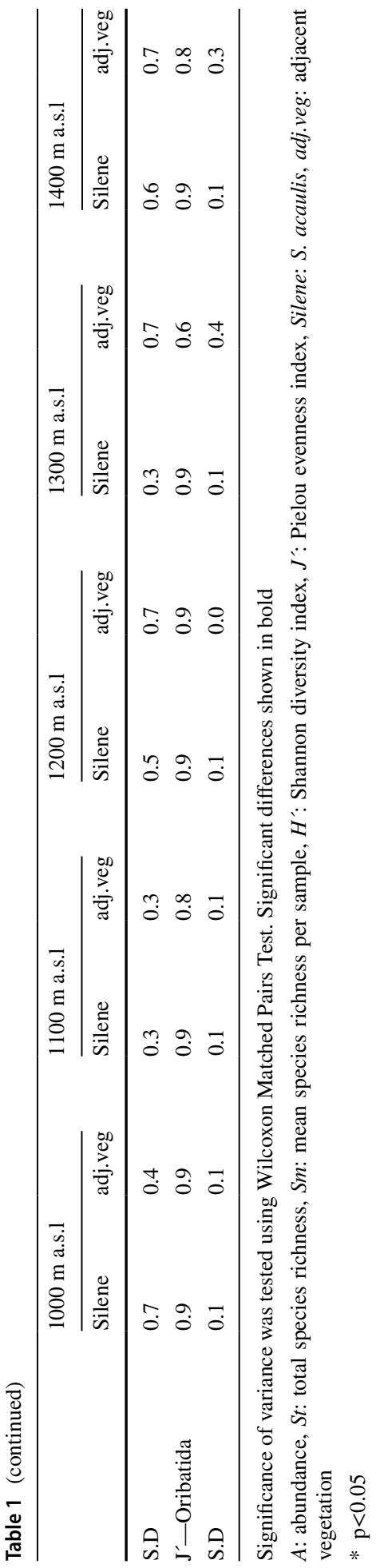


combined at $1100 \mathrm{~m}$ a.s.l. showed a significant difference (Table 1). Oribatids had the highest abundance of all soil mites across the elevation transect, representing more than $70 \%$ of all collected mites. Oribatid abundance under $S$. acaulis cushions increased with elevation to $1300 \mathrm{~m}$ a.s.l. and at $1400 \mathrm{~m}$ a.s.l. there was a decrease. The abundance of the mites under adjacent vegetation plots showed no distinct trend. The predatory groups Prostigmata and Gamasina had different abundance distributions between the two vegetation types at different elevation levels. Gamasina were more abundant under adjacent vegetation at 1000 and $1100 \mathrm{~m}$ a.s.l., but appeared in distinctly higher abundance under $S$. acaulis cushions at higher elevations, with a significant difference $(\mathrm{p}<0.05)$ only at the highest elevation $1400 \mathrm{~m}$ a.s.l. (Table 1). Prostigmata showed the opposite abundance distribution trend. These mites were distinctly more abundant under $S$. acaulis cushions up to $1200 \mathrm{~m}$ a.s.l., while their abundances at higher elevations were similar within both vegetation types. Similarly to oribatids, collembolans were more abundant under $S$. acaulis cushions, except at $1400 \mathrm{~m}$ a.s.l., where the abundance was higher under adjacent vegetation. A statistically significant effect $(\mathrm{p}<0.01)$ of vegetation type on totals of mites and collembolans, and on the oribatids and Gamasina groups, was obtained (Table 2). However, a significant effect of elevation or a combined effect of elevation and vegetation type on these microarthropod groups was not observed.

Total species richness of collembolans under $S$. acaulis cushions along the whole elevation transect was slightly higher $(S=34)$ than under adjacent vegetation $(S=31)$. Species richness within all $S$. acaulis cushions at the different elevations studied was also higher than under adjacent vegetation, except at $1000 \mathrm{~m}$ a.s.l. (Table 1). Total species richness of collembolans at each elevation and mean species richness per sample under both vegetation types decreased continuously to the highest elevation, with a significant difference at $1300 \mathrm{~m}$ a.s.l. $(\mathrm{p}<0.05)$. For oribatids, differences in total species richness (ie. all elevations together) between Silene cushions $(S=87)$ and adjacent vegetation $(S=67)$ were more distinct compared with collembolans. Species richness at each elevation, except $1100 \mathrm{~m}$ a.s.l., was higher under $S$. acaulis cushions than under adjacent vegetation (Table 1). Mean species richness of oribatids was significantly higher under $S$. acaulis cushions at 1300 and $1400 \mathrm{~m}$ a.s.1. $(\mathrm{p}<0.05)$.

Diversity and evenness indices of oribatids and collembolans under $S$. acaulis cushions compared with adjacent vegetation showed higher mean values at all elevation levels. For collembolans, the Shannon diversity index was significantly different for elevation at level $1300 \mathrm{~m}$ a.s.l. $(\mathrm{p}<0.05)$, while for oribatids the index was significantly different at elevation $1400 \mathrm{~m}$ a.s.l. $(\mathrm{p}<0.05)$ (Table 1). Significant effects of elevation and vegetation type on collembolan diversity, and of vegetation type on evenness index, were detected (Table 2). Oribatid diversity was significantly affected by the elevation and vegetation type.

In NMDS ordination, the best three-dimensional solution, for which the first two dimensions are shown in (Fig. 1), had final stress of $17.12(\mathrm{p}<0.001)$ after 500 iterations. This was confirmed by a Monte Carlo Permutation Test with $\mathrm{p}<0.005$, and mean stress of 17.45 for real data and 250 runs for both real and randomized data. The first three axes explained $38.1 \%, 20.3 \%$, and $16.5 \%$ of the variance, respectively. The NMDS results confirmed the impact of elevation on community composition. The diagram revealed the similarity of communities at lower elevations (1000 to $1200 \mathrm{~m})$, and more diverse communities at the two highest elevations. Using species dominance rank curves also revealed greater differences in collembolan and oribatid community structure between $S$. acaulis cushions and adjacent vegetation at the two highest elevations (Fig. 2 and Fig. 3).

Species of collembolans and oribatids were divided into three groups depending on their preference for vegetation types along the elevation gradient. The first group, 
Table 2 Statistical parameter estimates from repeated measure ANOVA analyses testing the effect of vegetation type, elevation, and their interaction on microarthropod groups abundance, species richness, diversity, and evenness indices

\begin{tabular}{|c|c|c|c|}
\hline Predictor & $\mathrm{F}$ & $\mathrm{p}$ & df \\
\hline \multicolumn{4}{|l|}{ A-total Acari } \\
\hline elevation & 1.748 & 0.179 & 4 \\
\hline vegetation type & 186.011 & $<0.001$ & $\mathbf{1}$ \\
\hline altitude*vegetation type & 2.095 & 0.119 & 4 \\
\hline \multicolumn{4}{|l|}{ A-Gamasina } \\
\hline elevation & 0.674 & 0.618 & 4 \\
\hline vegetation type & 131.665 & $<0.001$ & $\mathbf{1}$ \\
\hline altitude*vegetation type & 2.095 & 0.119 & 4 \\
\hline \multicolumn{4}{|l|}{ A-Oribatida } \\
\hline elevation & 1.642 & 0.203 & 4 \\
\hline vegetation type & 201.033 & $<0.001$ & $\mathbf{1}$ \\
\hline altitude*vegetation type & 1.461 & 0.251 & 4 \\
\hline \multicolumn{4}{|l|}{ A-Collembola } \\
\hline elevation & 2.089 & 0.120 & 4 \\
\hline vegetation type & 12.252 & $<0.01$ & 1 \\
\hline altitude*vegetation type & 0.075 & 0.989 & 4 \\
\hline \multicolumn{4}{|l|}{ S-Collembola } \\
\hline elevation & 10.831 & $<0.001$ & 4 \\
\hline vegetation type & 5.446 & 0.030 & 1 \\
\hline altitude*vegetation type & 0.706 & 0.597 & 4 \\
\hline \multicolumn{4}{|l|}{$H^{\prime}-$ Collembola } \\
\hline elevation & 10.223 & $<0.001$ & 4 \\
\hline vegetation type & 12.750 & $<0.01$ & 1 \\
\hline altitude*vegetation type & 0.477 & 0.752 & 4 \\
\hline \multicolumn{4}{|l|}{$J^{\prime}-$ Collembola } \\
\hline elevation & 1.138 & 0.367 & 4 \\
\hline vegetation type & 77.253 & $<0.001$ & 1 \\
\hline altitude*vegetation type & 1.001 & 0.430 & 4 \\
\hline \multicolumn{4}{|l|}{$S$-Oribatida } \\
\hline elevation & 2.624 & 0.065 & 4 \\
\hline vegetation type & 13.305 & $<0.01$ & 1 \\
\hline altitude*vegetation type & 1.507 & 0.238 & 4 \\
\hline \multicolumn{4}{|l|}{$H^{\prime}-$ Oribatida } \\
\hline elevation & 3.049 & 0.041 & 4 \\
\hline vegetation type & 14.706 & $<0.01$ & 1 \\
\hline altitude*vegetation type & 2.407 & 0.083 & 4 \\
\hline
\end{tabular}

Significant differences shown in bold. Oribatid evenness could not be tested due to non-normal data distribution even after transformation

$P$ : probability value, $d f$ : degrees of freedom, $A$ : abundance, $S$ : species richness, $H^{\prime}$ : Shannon diversity index, $J^{\prime}$ : Pielou evenness index. Data Box Cox-transformed to normalized distribution

with the majority of species, preferred S. acaulis cushions (collembolans: Ceratophysella scotica, Desoria violacea, Folsomia palearctica, F. quadrioculata, Friesea mirabilis, F. truncata, Isotomiella minor, Parisotoma notabilis; oribatids: Ceratozetes 


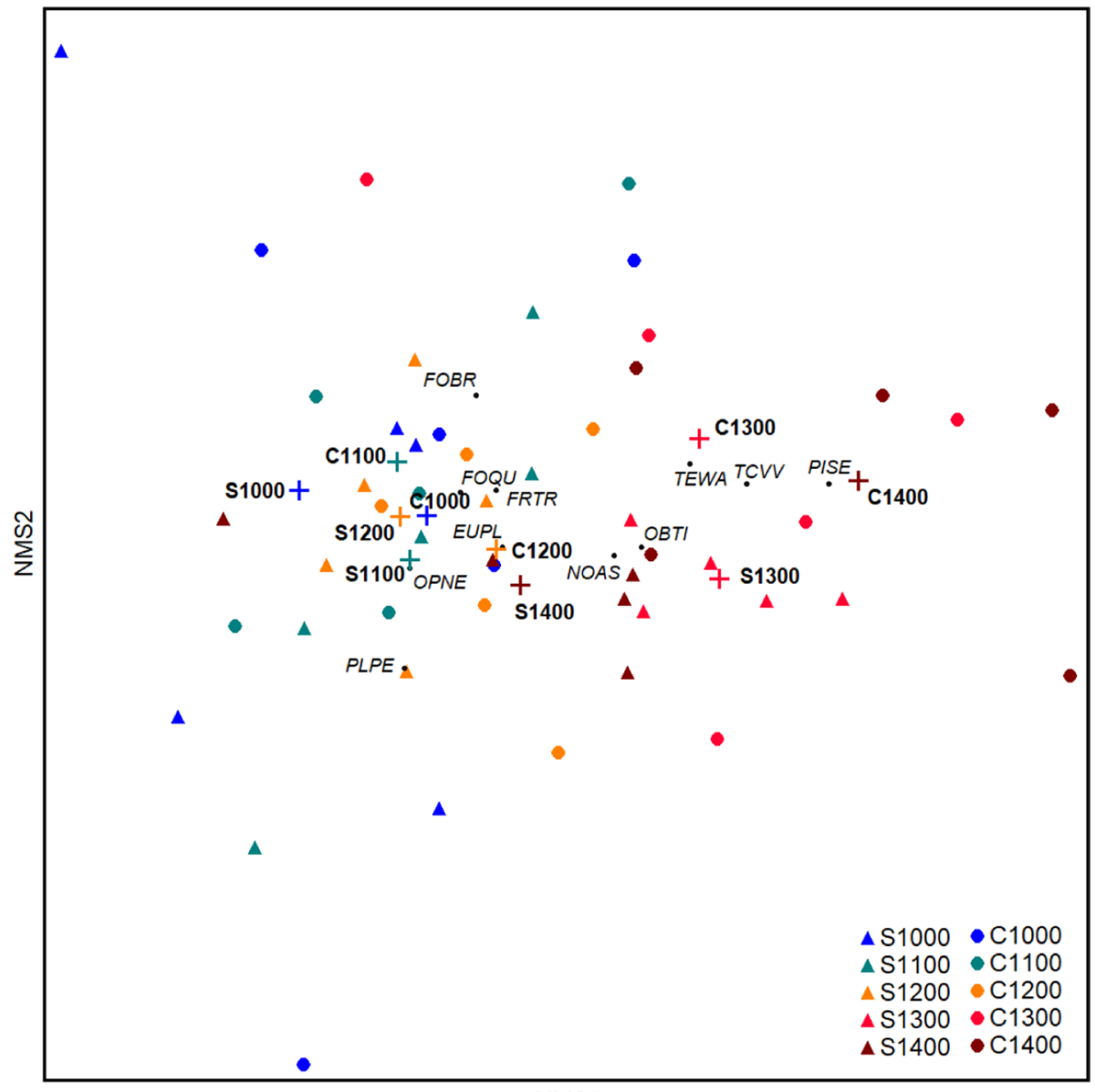

NMS1

Fig. 1 Non-metric multidimensional scaling (NMDS) ordination plot of collembolan and oribatid communities under $S$. acaulis cushions and adjacent vegetation along an elevation gradient in an alpine region in northern Sweden. S - S. acaulis cushions centroids, C - adjacent vegetation centroids, 1000-1400 - elevation levels; for species abbreviations see Table 3

thienemanni, Dissorhina ornata, Eupelops plicatus, Nothrus aff. silvestris, Oribatula tibialis, Platynothrus peltifer) (Table S1). The second group, which showed higher abundances under adjacent vegetation, comprised a few collembolan species, namely Desoria olivacea, Folsomia brevicauda and Tetracanthella wahlgreni, and the oribatid mite Tectocepheus velatus velatus. The third group of species showed no distinct preference for vegetation type (collembolans: Isotoma viridis, Pseudanurophorus binoculatus, Pseudisotoma sensibilis; oribatids: Oppiella neerlandica).

Variance of abundance between $S$. acaulis cushions and adjacent vegetation was tested for the most abundant collembolan and oribatid species (Table 3), but no significant differences were observed. 

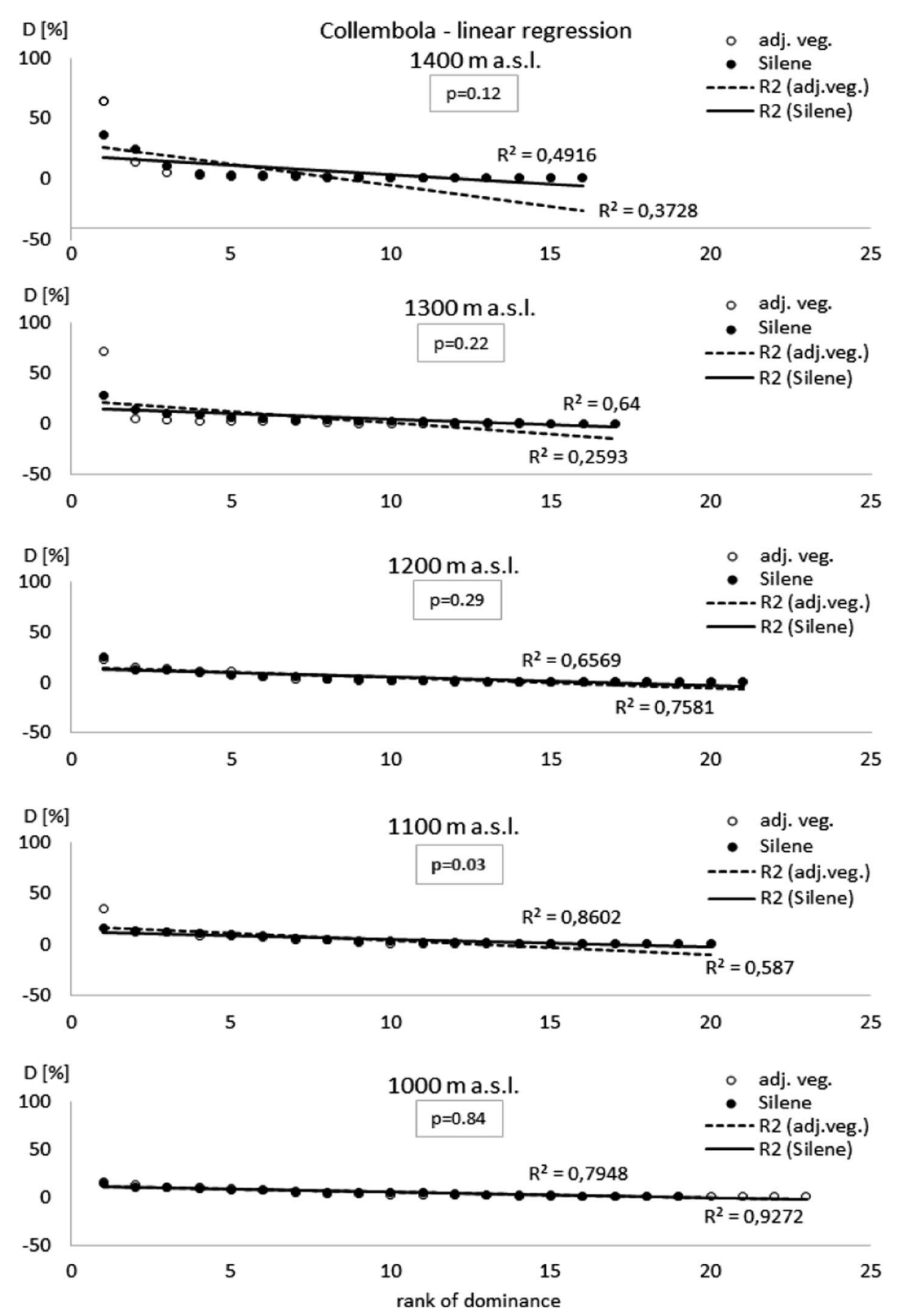

Fig. 2 Ranking of collembolan species dominance under S. acaulis cushions and adjacent vegetation along an elevation gradient. Silene-dominance of species observed under S. acaulis cushions, adj.veg.—dominance of species observed under adjacent vegetation 

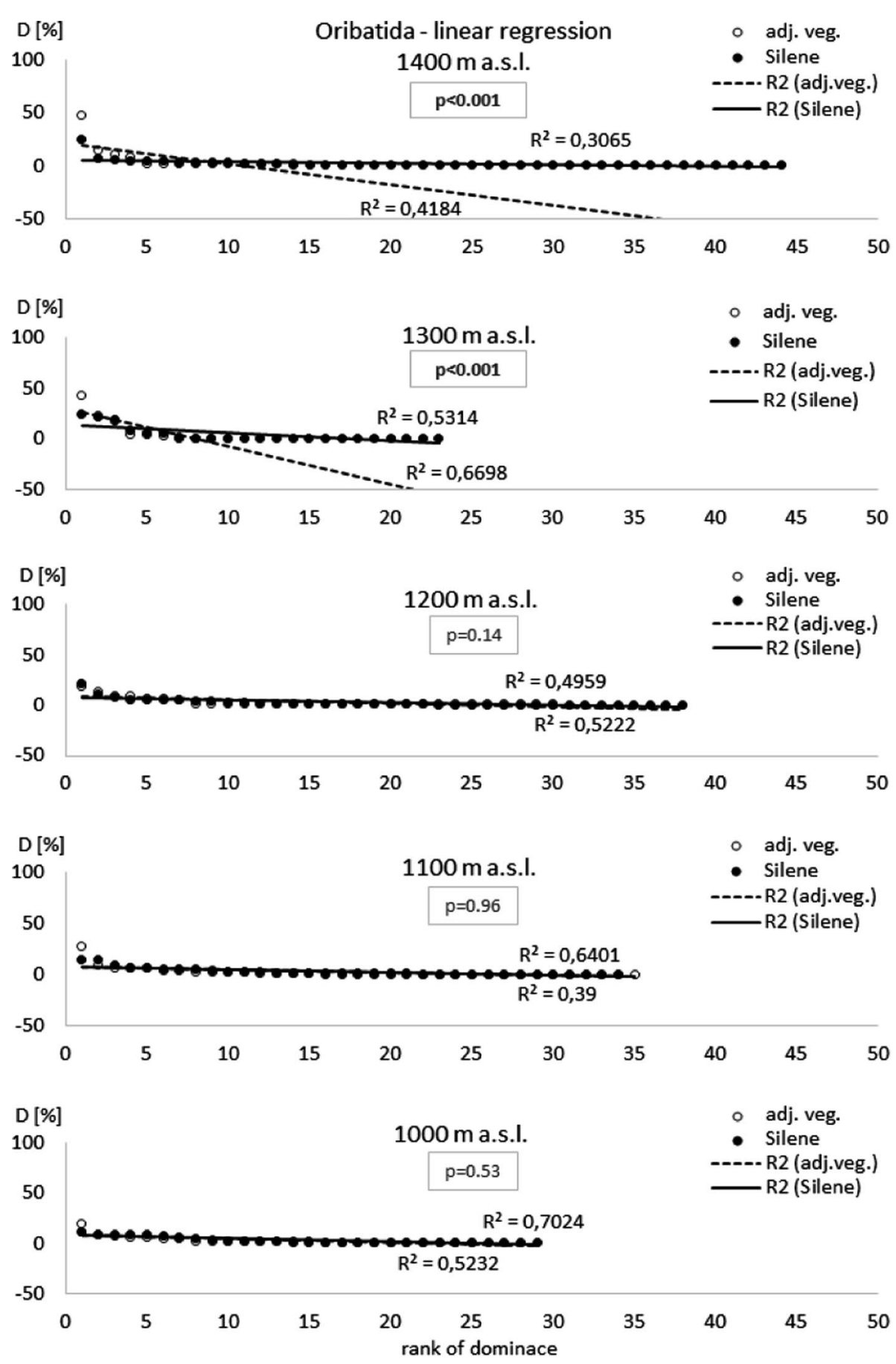

Fig. 3 Ranking of oribatid species dominance under S. acaulis cushions and adjacent vegetation along an elevation gradient. Silene—-dominance of species observed under S. acaulis cushions, adj.veg.—dominance of species observed under adjacent vegetation 


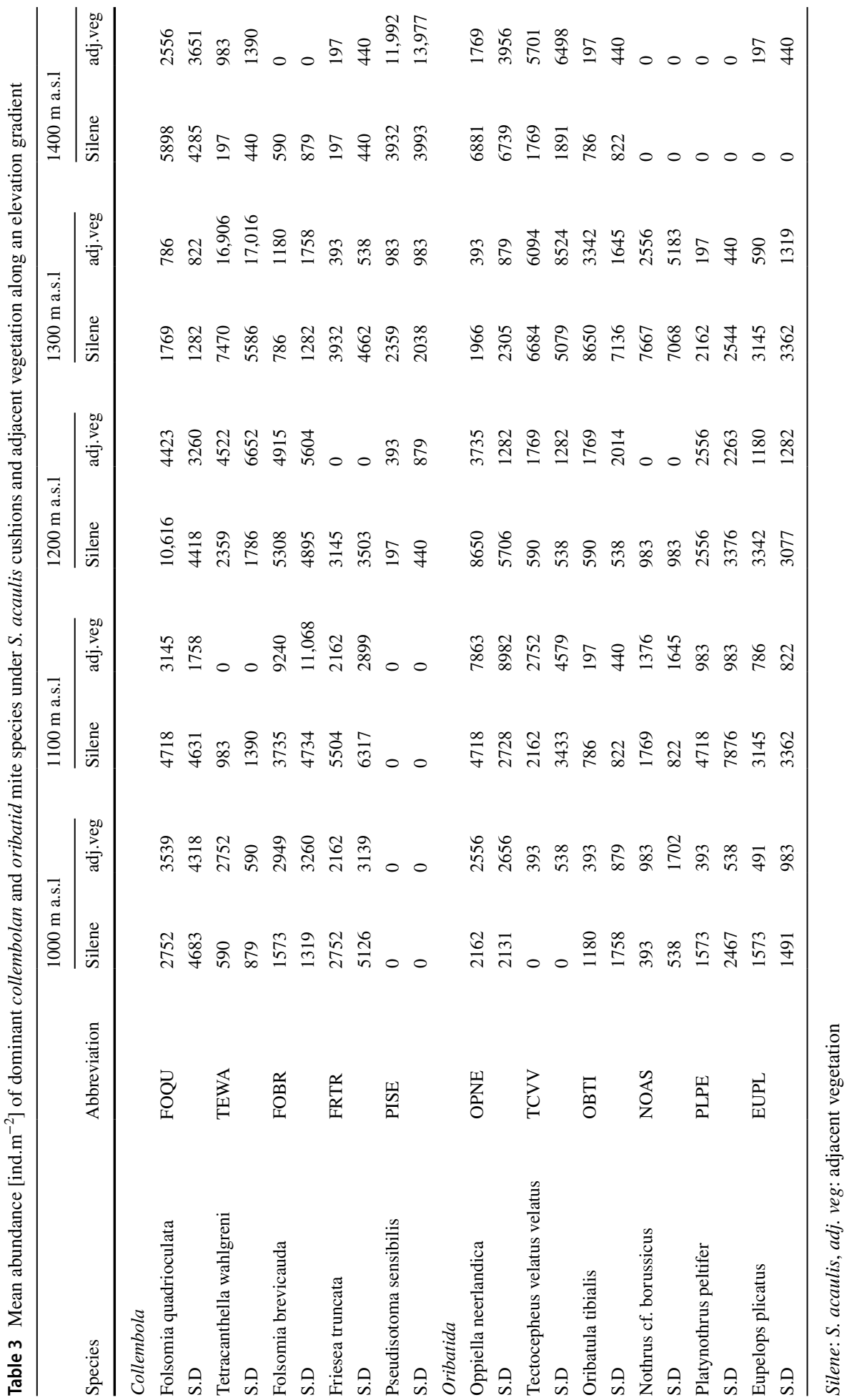




\section{Comparison of Diapensia lapponica and adjacent vegetation}

In total, 313 collembolans and 341 soil mite individuals were collected under D. lapponica and adjacent vegetation on the exposed mountain ridge (1000 $\mathrm{m}$ a.s.1.). The collembolans belonged to six families, 14 genera, and 17 species. More than $90 \%$ of Acari consisted of oribatids, represented by 18 species, 14 genera, and nine families. Astigmatina were not detected under D. lapponica cushions or under adjacent vegetation.

Total mites, saprophagous oribatids, and collembolans showed significantly $(\mathrm{p}<0.05)$ higher abundance under D. lapponica cushions than under adjacent vegetation (Table 4). Predatory Gamasina mites showed higher abundance under $D$. lapponica cushions, but this relationship was not significant $(\mathrm{p}>0.1)$. The abundance of mostly predaceous Prostigmata did not differ between vegetation types.

Table 4 Mean abundance [ind. $\mathrm{m}^{-2}$ ] of soil microarthropod groups and species richness and diversity indices of collembolans and oribatids under $D$. lapponica cushions and adjacent vegetation

\begin{tabular}{|c|c|c|}
\hline & Diapensia lapponica & $\begin{array}{l}\text { adjacent } \\
\text { vegeta- } \\
\text { tion }\end{array}$ \\
\hline A-total Acari & 16,569 & 7372 \\
\hline S.D & 9139 & 4606 \\
\hline A-Prostigmata & 351 & 351 \\
\hline S.D & 623 & 828 \\
\hline A-Gamasina & 562 & 211 \\
\hline S.D & 743 & 419 \\
\hline A-Uropodina & 70 & 70 \\
\hline S.D & 263 & 263 \\
\hline A-Oribatida & 15,587 & 6740 \\
\hline S.D & 9372 & 4078 \\
\hline A-Collembola & 15,165 & 6810 \\
\hline S.D & 9048 & 4713 \\
\hline St-Collembola & 17 & 7 \\
\hline Sm-Collembola & 4.6 & 2.4 \\
\hline S.D & 2.1 & 1.3 \\
\hline $\mathrm{H}^{\prime}-$ Collembola & 1.2 & 0.6 \\
\hline S.D & 0.3 & 0.4 \\
\hline $\mathrm{J}^{\prime}-$ Collembola & 0.8 & 0.7 \\
\hline S.D & 0.1 & 0.4 \\
\hline St-Oribatida & 14 & 11 \\
\hline $\mathrm{Sm}$-Oribatida & 3.9 & 2.8 \\
\hline S.D & 1.4 & 1.4 \\
\hline $\mathrm{H}^{\prime}$-Oribatida & 1.1 & 0.8 \\
\hline S.D & 0.4 & 0.5 \\
\hline $\mathrm{J}^{\prime}-$ Oribatida & 0.9 & 0.7 \\
\hline S.D & 0.2 & 0.4 \\
\hline
\end{tabular}

Astigmatina were not tested due to high number of zero values. Significance of variance tested using Mann-Whitney Test. Significant results shown in bold

$A$ : abundance, St: total species richness, $S m$ : mean species richness per sample, $H^{\prime}$ : Shannon diversity index, $J^{\prime}$ : Pielou evenness index

* $\mathrm{p}<0.01$ 
Total species richness was higher under D. lapponica cushions than under adjacent vegetation in both main microarthropod groups (collembolans and oribatids). Mean species richness per sample was also higher under D. lapponica cushions than under adjacent vegetation, but only collembolans showed a significant difference (Table 4). All collembolan species recorded under adjacent vegetation also appeared under D. lapponica cushions. The majority of oribatid and collembolan species common to both treatments were more abundant under D. lapponica cushions (Table S2). Only the oribatid mite Mycobates sarakensis showed higher abundance under adjacent vegetation. Testing of the variance of abundance was performed on 11 species in total. Significantly higher abundances of the springtails Friesea truncata and Folsomia quadrioculata and the oribatid mite Ceratozetes thienemanni were observed under Diapensia cushions (Table 5). Of the two dominant microarthropod groups, only collembolans showed significantly higher diversity indices under $D$. lapponica cushions compared with the adjacent vegetation (Table 4).

Table 5 Mean abundance [ind. $\mathrm{m}^{-2}$ ] of dominant collembolan and oribatid mite species under D. lapponica cushions and adjacent vegetation

\begin{tabular}{|c|c|c|c|}
\hline Species & Abbreviation & $\begin{array}{l}\text { Diapensia } \\
\text { lapponica }\end{array}$ & $\begin{array}{l}\text { adjacent } \\
\text { vegeta- } \\
\text { tion }\end{array}$ \\
\hline \multicolumn{4}{|l|}{ Collembola } \\
\hline Folsomia brevicauda & FOBR & 3440 & 3651 \\
\hline S.D & & 2719 & 4453 \\
\hline Folsomia quadrioculata & FOQU & 5055 & 1755 \\
\hline S.D & & 2856 & 1598 \\
\hline Friesea truncata & FRTR & 1896 & 140 \\
\hline S.D & & 1701 & 357 \\
\hline Parisotoma notabilis & PSNO & 1334 & 421 \\
\hline S.D & & 3099 & 922 \\
\hline Tetracanthella wahlgreni & TEWA & 632 & 632 \\
\hline S.D & & 2364 & 1131 \\
\hline \multicolumn{4}{|l|}{ Oribatida } \\
\hline Tectocephaeus velatus velatus & TCVV & 2949 & 2036 \\
\hline S.D & & 2726 & 2452 \\
\hline Ceratozetes thienemanni & $\mathrm{CZTH}$ & 3791 & 1053 \\
\hline S.D & & 3948 & 980 \\
\hline Oppiella acuminata & OPAC & 1545 & 70 \\
\hline S.D & & 2239 & 263 \\
\hline Dissorhina ornata & DIOR & 1194 & 140 \\
\hline S.D & & 2118 & 357 \\
\hline Mycobates sarekensis & MYSA & 351 & 983 \\
\hline S.D & & 489 & 944 \\
\hline
\end{tabular}

Significance of variance estimated using Mann-Whitney Test. Significant differences shown in bold

* $\mathrm{p}<0.01$ 


\section{Discussion}

Nurse plants modify the conditions in stressful environments by providing a microclimate under their canopies. Thus they can increase species richness (Nuñez et al. 1999; Arroyo and Cavieres 2003; Badano and Marquet 2009), abundance (Cavieres and Arroyo 2002; Badano et al. 2007; Sklenář 2009), phylogenetic diversity (Butterfield et al. 2013), and survival of other plant species (Cavieres et al. 2007, 2008; Badano et al. 2007). In this study in an alpine region in Sweden, we observed a positive effect of cushion plants on soil microarthropods. As hypothesized, we found that the cushion plants $S$. acaulis and D. lapponica had higher species richness of collembolans and oribatids than adjacent vegetation. The positive facilitation effect of $S$. acaulis increased with increasing elevation. In contrast, a study in high-elevation New Zealand only found a positive impact of cushion plants on abundance and richness of mites (Oribatida, Mesostigmata, Prostigmata), while collembolan abundance was higher in adjacent vegetation (Minor et al. 2016). Those authors suggested that the difference between organism groups may have been due to mites being more sensitive to disturbances; collembolans are more mobile and more generalist feeders, are more opportunistic, and colonize new patches between cushion plants.

Soils under S. acaulis and other cushion plants have been shown to have higher moisture, organic $\mathrm{C}$, salinity, total $\mathrm{N}$, and $\mathrm{C} / \mathrm{N}$ ratio, and lower $\mathrm{pH}$ than soils under adjacent vegetation (Cavieres et al. 2007; Antonsson et al. 2009; Bonanomi et al. 2015; Minor et al. 2016). As bacterial and fungal communities are frequently positively associated with higher soil moisture and organic $\mathrm{C}$ and $\mathrm{N}$, soils under cushions could potentially have larger biomass of bacteria and fungi (Zumsteg et al. 2013), both of which are important food sources for collembolans and mites. The morphology of S. acaulis changes along the elevation gradient, with looser and flatter cushions at lower elevation and more dense and tight dome-shaped cushions at higher elevation (Bonanomi et al. 2015). More dense $S$. acaulis cushions might retain moisture and stabilize temperature more effectively, thus supporting richer bacterial and fungal communities.

There is a lack of information on soil properties under D. lapponica cushions compared with adjacent vegetation. D. lapponica is a long-lived plant and forms dome-shaped dense cushions (Day and Scott 1981) similar to those of S. acaulis and other cushion-forming species. It is often found in areas with cool summer temperatures (Damman 1976) and on acid, low-nutrient, or toxic soils (Day and Scott 1981), conditions which exclude many of its potential competitors. Cushions of Diapensia also act as heat traps and can considerably increase the soil temperature at night (Day and Scott 1981). These reports suggest that $D$. lapponica can influence soil properties under cushions, which could explain the distinct facilitation effect of $D$. lapponica on soil fauna observed in our study. There is likely to be a more stable and favourable microclimate for fauna in terms temperature and humidity.

A previous study on the microscale distribution of microarthropods in high-Arctic Svalbard found that collembolans, but not mites, showed higher abundance under cushions of $S$. acaulis than under five other plant species in the adjacent vegetation, with no difference in species richness of collembolans or mites between the other plant species (Coulson et al. 2003). However, that study was not carried out along an elevation gradient, unlike the present study in northern Sweden. Moreover, high-Arctic Svalbard encompasses more extreme environments, with markedly diminished species diversity (6 collembolan species, 7 mite species) compared with our alpine sub-Arctic site in Sweden (41 collembolan species, 107 oribatid species). 
Similarly, a study carried out in high-alpine Chile found that ladybird beetle abundance was higher under cushion plants than under the surrounding vegetation, while a greenhouse experiment showed that, under milder temperatures, the beetles did not prefer cushions (Molina-Montenegro et al. 2006). Thus, the facilitation effect was only expressed under harsher microclimatic conditions. An association between facilitation effect and harsher microclimatic conditions could also explain why we observed more distinct differences in species richness, abundance, and diversity and evenness indices between cushions, compared with adjacent vegetation, at sites at the highest elevations ( $S$. acaulis, 1300 and $1400 \mathrm{~m}$ a.s.l.) and on the exposed ridge (D. lapponica) in alpine Sweden examined in this study.

A study examining S. acaulis and its role as a facilitator species in the Canadian Rocky Mountains found that $S$. acaulis had higher visitation rate and diversity of both ground arthropods and pollinators than all non-cushion plants (Reid and Lortie 2012). Similarly, richness, abundance, and diversity index of above-ground arthropods were all higher under cushions of $S$. acaulis compared with adjacent vegetation in a study in the same area (Molenda et al. 2012). Another study at Latnjajaure, covering the same transect as in the present study, found that cushions of $S$. acaulis had a facilitation effect on other plants at higher elevations (Antonsson et al. 2009).

Rank-abundance (relative abundance) diagrams are widely used to document complex community structure (Begon et al. 2006). Steeper curves indicate more unbalanced community structure, with a few dominant and a high number of recedent species (Lindberg et al. 2002; Camann et al. 2008; Luptáčik et al. 2012). In the species dominance rank curves obtained in the present study, collembolan and oribatid mite communities displayed more visible differences between $S$. acaulis cushions and adjacent vegetation at the two highest elevations with harsher microclimatic conditions, while communities with more similar structure were observed at lower elevations with a milder microclimate. The vegetation that closely surrounded $S$. acaulis cushions at lower elevations $(1000,1100,1200 \mathrm{~m}$ a.s.1.) (Antonsson et al. 2009) probably created more similar microclimatic conditions to those under Silene cushions, thus enabling movement of microarthropods between $S$. acaulis cushions and adjacent vegetation. At the highest elevations (1300, $1400 \mathrm{~m}$ a.s.l.), $S$. acaulis cushions and adjacent vegetation formed more or less isolated patches on the bedrock, and thus movement of microarthropods between $S$. acaulis cushions and adjacent vegetation more difficult. The adjacent vegetation consisted mainly of lichens and mosses, which likely also offered different soil conditions compared with those under S. acaulis cushions and had different community properties and structure.

Harsh microclimatic conditions on the exposed ridge, similar to those at the highest elevations (1300, $1400 \mathrm{~m}$ a.s.l.) of the gradient with $S$. acaulis, probably resulted in more favorable soil conditions under D. lapponica cushions compared with under poor adjacent vegetation (Molau 1996, 1997), explaining the significant differences in total Acari, oribatid, and collembolan abundance.

A previous study in the Latnjajaure valley found that collembolans under three different plant communities were resistant to two decades of experimental warming (Alatalo et al. 2015). However, abundance of juvenile mites, but not adults, declined with longterm warming (Alatalo et al. 2017b), most likely because juveniles are more soft-bodied than adults and thus more vulnerable to desiccation (Day et al. 2009; Bokhorst et al. 2012). That means there was a lower survival rate of juveniles to adulthood at higher temperatures. In addition, the warmed plots had no barriers within the soil, so adult soil mites could have re-colonized the warmed plots even when the conditions were unfavorable for juveniles (Alatalo et al. 2017b). Additionally, warmed plots could potentially 
have allowed mites to reproduce and hatch earlier and grow faster than those in the control plots, so at the time of sampling many of them may have already developed into adults, decreasing the number of juveniles in the samples (Alatalo et al. 2017b).

However, it should be noted that the sampling in those studies was not focused on cushion plants, but performed randomly under the vegetation within experimental plots. Similarly, experimental warming in laboratory and field environment in high-Arctic Svalbard had no direct negative effect on collembolans and mites, while warming experiments combined with decreased moisture levels in the field had a large negative impact on collembolans (Hodkinson et al. 1996). Mites were unaffected in that study, suggesting that collembolans are more vulnerable to desiccation than mites.

Mites are under severe threat globally due to habitat destruction and degradation, with climate change likely to exacerbate the effects of the other drivers at an increasing rate (Sullivan and Ozman-Sullivan, 2021), although the mites and collembolans in alpine and Arctic areas are not likely to be directly negatively affected by increased temperatures due to climate change. However, experimental (Alatalo and Little 2014; Villellas et al. 2019) and monitoring studies (Doak and Morris 2010) suggest that $S$. acaulis may be vulnerable to climate change. Therefore, also collembolan and mite communities inhabiting soil under $S$. acaulis cushions could be indirectly vulnerable. In addition, recent modeling studies have estimated that more than $50 \%$ of current locations of S. acaulis are likely to be outside its future climatic hypervolume in North America (Ferrarini et al. 2019b). In the British Isles, the majority of its current locations will likely become unsuitable in the future (Ferrarini et al. 2019a). Similarly, D. lapponica is vulnerable to climate change, as earlier onset of snowmelt will expose it to increased risk of early frost events, which increase mortality when the plant is not protected by snow cover (Molau 1996). In this study, the species richness of both collembolans and mites was higher under cushions of $S$. acaulis and D. lapponica than under adjacent vegetation. If the abundance of these cushion plants declines in the future due to climate change, this is likely to have adverse effects on microarthropod diversity in alpine and Arctic regions.

\section{Conclusions}

In the subarctic study area, abundance, species richness and diversity indices of two major groups of soil microarthropods were all higher under S. acaulis and D. lapponica cushions than under adjacent vegetation, suggesting that cushion plants facilitate soil microarthropod communities. Significant impacts of elevation and vegetation type on collembolans and soil mites were demonstrated. NMDS analysis and species rank curves revealed differing microarthropod communities under the two different vegetation types at high-elevation sites (above $1300 \mathrm{~m}$ a.s.l.). This indicates that the level of facilitation of soil microarthropods by cushion plants increases with elevation and therefore plays a more critical role under harsher environmental conditions.

Supplementary Information The online version contains supplementary material available at https://doi. org/10.1007/s10531-021-02247-y.

Acknowledgements We thank the Abisko Scientific Research Station for hospitality during fieldwork.

Author contributions The study was designed by J.M.A. Fieldwork was performed by J.M.A., P.C., and P.L. Micro-arthropod identification was made by P.C, P.J., and P.L. D.M performed statistical analyses. J.M.A., 
P.L. and L.K. were the main authors of the paper. All co-authors contributed to manuscript revisions and agree with the final version.

Funding This study was funded by Carl Tryggers stiftelse för vetenskaplig forskning and Qatar Petroleum (through J.M.A). Open access funding provided by the Qatar National Library.

Data availability Data used for analysis accompany this article as electronic supplementary material.

\section{Declarations}

Conflict of interests The authors declare no conflict of interests.

Open Access This article is licensed under a Creative Commons Attribution 4.0 International License, which permits use, sharing, adaptation, distribution and reproduction in any medium or format, as long as you give appropriate credit to the original author(s) and the source, provide a link to the Creative Commons licence, and indicate if changes were made. The images or other third party material in this article are included in the article's Creative Commons licence, unless indicated otherwise in a credit line to the material. If material is not included in the article's Creative Commons licence and your intended use is not permitted by statutory regulation or exceeds the permitted use, you will need to obtain permission directly from the copyright holder. To view a copy of this licence, visit http://creativecommons.org/licenses/by/4.0/.

\section{References}

Alatalo JM, Little CJ (2014) Simulated global change: contrasting short and medium term growth and reproductive responses of a common alpine/Arctic cushion plant to experimental warming and nutrient enhancement. Springerplus 3:157. https://doi.org/10.1186/2193-1801-3-157

Alatalo JM, Molau U (1995) Effect of altitude on the sex ratio in populations of Silene acaulis (Caryophyllaceae). Nord J Bot 15:251-256. https://doi.org/10.1111/j.1756-1051.1995.tb00150.x

Alatalo JM, Jägerbrand AK, Čuchta P (2015) Collembola at three alpine subarctic sites resistant to twenty years of experimental warming. Sci Rep 5:18161. https://doi.org/10.1038/srep18161

Alatalo JM, Jägerbrand AK, Chen S, Molau U (2017a) Responses of lichen communities to 18 years of natural and experimental warming. Ann Bot 120:159-170

Alatalo JM, Jägerbrand AK, Juhanson J et al (2017b) Impacts of twenty years of experimental warming on soil carbon, nitrogen, moisture and soil mites across alpine/subarctic tundra communities. Sci Rep 7:44489. https://doi.org/10.1038/srep44489

Antonsson H, Björk RRG, Molau U (2009) Nurse plant effect of the cushion plant Silene acaulis (L.) Jacq. in an alpine environment in the subarctic Scandes. Sweden Plant Ecol Divers 2:17-25

Arredondo-Núñez A, Badano E, Bustamante R (2009) How beneficial are nurse plants? A meta-analysis of the effects of cushion plants on high-Andean plant communities. Community Ecol 10:1-6

Arroyo M, Cavieres L (2003) Positive associations between the cushion plant Azorella monantha (Apiaceae) and alpine plant species in the Chilean Patagonian Andes. Plant Ecol 169:121-129

Badano E, Cavieres L (2006) Impacts of ecosystem engineers on community attributes: effects of cushion plants at different elevations of the Chilean Andes. Divers Distrib 12(4):388-396

Badano EI, Marquet PA (2009) Biogenic habitat creation affects biomass-diversity relationships in plant communities. Perspect in Plant Ecol, Evolution Syst 11:191-201

Badano EI, Villarroel E, Bustamante RO et al (2007) Ecosystem engineering facilitates invasions by exotic plants in high-Andean ecosystems. J Ecol 95:682-688. https://doi.org/10.1111/j.1365-2745.2007. 01262.x

Begon M, Townsend CR, Harper JL (2006) Ecology: from individuals to ecosystems. Oxford, Blackwell

Bokhorst S, Phoenix GK, Bjerke JW et al (2012) Extreme winter warming events more negatively impact small rather than large soil fauna: shift in community composition explained by traits not taxa. Glob Change Biol 18:1152-1162

Bonanomi G, Stinca A, Chirico GB et al (2015) Cushion plant morphology controls biogenic capability and facilitation effects of Silene acaulis along an elevation gradient. Funct Ecol N/a-N/a. https://doi.org/10. $1111 / 1365-2435.12596$ 
Bretfeld G (1999) Synopses on palaearctic collembola: symphypleona. In: Dunger W (ed) Abhandlungen und Berichte des Naturkundemuseums. Staatlicjes Museum für Naturkunde Görlitz 71:1-318

Bronstein JL (2009) The evolution of facilitation and mutualism. J Ecol 97:1160-1170

Brooker RW, Maestre FT, Callaway RM et al (2008) Facilitation in plant communities: the past, the present, and the future. J Ecol 96:18-34. https://doi.org/10.1111/j.1365-2745.2007.01295.x

Butterfield BJ, Cavieres LA, Callaway RM et al (2013) Alpine cushion plants inhibit the loss of phylogenetic diversity in severe environments. Ecol Lett 16:478-486. https://doi.org/10.1111/ele.12070

Callaway R, Walker L (1997) Competition and facilitation: a synthetic approach to interactions in plant communities. Ecology 78(7):1958-1965

Camann MA, Gillette NE, Lamoncha KL, Mori SR (2008) Response of forest soil Acari to prescribed fire following stand structure manipulation in the southern Cascade Range. Can J for Res 38:956-968

Cardinale BJ, Palmer MA, Collins SL (2002) Species diversity enhances ecosystem functioning through interspecific facilitation. Nature 415:426-429

Cavieres L, Arroyo M (2002) Nurse effect of Bolax gummifera cushion plants in the alpine vegetation of the Chilean Patagonian Andes. J Veg Sci 13:547-554

Cavieres LA, Badano EI, Sierra-Almeida A, Molina-Montenegro MA (2007) Microclimatic modifications of cushion plants and their consequences for seedling survival of native and non-native herbaceous species in the high Andes of central Chile. Arct, Antarct, Alp Res 39(2):229-236

Cavieres LA, Quiroz CL, Molina-Montenegro MA (2008) Facilitation of the non-native Taraxacum officinale by native nurse cushion species in the high Andes of central Chile: are there differences between nurses? Funct Ecol 22:148-156

Choler P, Michalet R, Callaway RM (2001) Facilitation and competition on gradients in alpine plant communities. Ecology 82:3295-3308. https://doi.org/10.1890/0012-9658(2001)082[3295:FACOGI]2.0.CO;2

Coulson SJ, Hodkinson ID, Webb NR (2003) Microscale distribution patterns in high Arctic soil microarthropod communities: the influence of plant species within the vegetation mosaic. Ecography 26:801-809

Crossley DA, Blair JM (1991) A high-efficiency, "low-technology" Tullgren-type extractor for soil microarthropods. Agric, Ecosyst Environ 34:187-192. https://doi.org/10.1016/0167-8809(91)90104-6

Damman AWH (1976) Plant distribution in Newfoundland especially in relation to summer temperatures measured with the sucrose inversion method. Can J Bot 54:1561-1685

Day RT, Scott PJ (1984) Biology of Diapensia lapponica in Newfoundland. Can Field-Nat 98:425-439

Day TA, Ruhland CT, Strauss SL et al (2009) Response of plants and the dominant microarthropod, Cryptopygus antarcticus, to warming and contrasting precipitation regimes in Antarctic tundra. Glob Change Biol 15:1640-1651. https://doi.org/10.1111/j.1365-2486.2009.01919.x

Doak DF, Morris WF (2010) Demographic compensation and tipping points in climate-induced range shifts. Nature 467:959-962. https://doi.org/10.1038/nature09439

Elberling H (2001) Pollen limitation of reproduction in a subarctic-alpine population of Diapensia lapponica (Diapensiaceae). Nord J Bot 21:277-282

Ferrarini A, Alsafran MH, Dai J, Alatalo JM (2019a) Improving niche projections of plant species under climate change: Silene acaulis on the British Isles as a case study. Clim Dyn 52:1413-1423. https://doi.org/10. 1007/s00382-018-4200-9)

Ferrarini A, Dai J, Bai Y, Alatalo JM (2019b) Redefining the climate niche of plant species: a novel approach for realistic predictions of species distribution under climate change. Sci Total Environ 671:1086-1093

Fjellberg A (1998) The Collembola of Fennoscandia and Denmark, Part I: Poduromorpha. In: Michelsen V (ed) Kristensen NP. Fauna Entomologica Scandinavica, Leiden

Fjellberg A (2007) The Collembola of Fennoscandia and Denmark, Part II: Entomobryomorpha and Symphypleona. In: Michelsen V (ed) Kristensen NP. Fauna Entomologica Scandinavica, Leiden

Gehring JL, Delph LF (1999) Fine-scale genetic structure and clinal variation in Silene acaulis despite high gene flow. Heredity 82:628-637

Gussarova G, Allen GA, Mikhaylova Y et al (2015) Vicariance, long-distance dispersal, and regional extinction-recolonization dynamics explain the disjunct circumpolar distribution of the arctic-alpine plant Silene acaulis. Am J Bot 102:1703-1720

Hauri H, Schröter C (1914) Versuch einer Uebersicht der siphonogamen Polsterpflanzen. Engler's Botanische Jahrbücher 50:618-656

Hodkinson ID, Coulson SJ, Webb NR, Block W (1996) Can high arctic soil microarthropods survive eleveated summer temperatures? Funct Ecol 10(3):314-321

Ikeda H, Senni K, Fujii N, Setoguchi H (2008) Survival and genetic divergence of an arctic-alpine plant, Diapensia lapponica subsp. obovata (Fr. Schm.) Hultén (Diapensiaceae), in the high mountains of central Japan during climatic oscillations. Plant Syst Evol 272:197-210

Janssens F, Christiansen KA (2011) Class Collembola Lubbock, 1870. In: Zhang, Z.-Q. (Ed) Animal biodiversity: an outline of higher-level classification and survey of taxonomic richness. Zootaxa 3148:192-194 
Junttila O, Robberecht R (1993) The Influence of Season and Phenology on Freezing Tolerance in Silene acaulis L., a Subarctic and Arctic Cushion Plant of Circumpolar Distribution. Ann Bot 71:423-426

L'uptáčik P, Miklisová D, Kováč L (2012) Diversity and community structure of soil Oribatida (Acari) in an arable field with alluvial soils. Eur J Soil Biol 50:97-105

Lindberg N, Engtsson JB, Persson T (2002) Effects of experimental irrigation and drought on the composition and diversity of soil fauna in a coniferous stand. J Appl Ecol 39(6):924-936

Lowry R (2021) VassarStats: Website for statistical computation. 1998-2021. Available online: http://vassa rstats.net/ (May 10th 2021).

McCune: B, Mefford MJ 2016 PC-ORD, version 7.2 (Multivariate analysis of ecological data). MjM Software

Milbau A, Graae BJ, Shevtsova A, Nijs I (2009) Effects of a warmer climate on seed germination in the subarctic. Ann Bot 104:287-296. https://doi.org/10.1093/aob/mcp117

Minor MA, Babenko AB, Ermilov SG et al (2016) Effects of cushion plants on high-altitude soil microarthropod communities: cushions increase abundance and diversity of mites (Acari), but not springtails (Collembola). Arct Antarct Alp Res 48:485-500

Molau U (1996) Climatic impacts on flowering, growth, and vigour in an arctic-alpine cushion plant, Diapensia lapponica, under different snow cover regimes. Ecol Bull 210-219

Molau U (1997) Age-related growth and reproduction in Diapensia lapponica, an arctic-alpine cushion plant. Nord J Bot 17:225-234. https://doi.org/10.1111/j.1756-1051.1997.tb00314.x

Molau U, Alatalo JM (1998) Responses of subarctic-alpine plant communities to simulated environmental change: biodiversity of bryophytes, lichens, and vascular plants. Ambio 27:322-329

Molenda O, Reid A, Lortie CJ (2012) The alpine cushion plant Silene acaulis as foundation species: a bug's-eye view to facilitation and microclimate. PLoS ONE 7:e37223. https://doi.org/10.1371/journal.pone.0037223

Molina-Montenegro MA, Badano EI, Cavieres LA (2006) Cushion plants as microclimatic shelters for two ladybird beetles species in alpine zone of Central Chile. Arct Antarct Alp Res 38:224-227

Morris WF, Doak DF (1998) Life history of the long-lived gynodioecious cushion plant Silene acaulis (Caryophyllaceae), inferred from size-based population projection matrices. Am J Bot 85:784-793. https://doi. org/10.2307/2446413

Nuñez CI, Aizen MA, Ezcurra C (1999) Species associations and nurse plant effects in patches of high-Andean vegetation. J Veg Sci 10:357-364

Olszanowski Z (1996) A monograph of the Nothridae and Camisiidae of Poland (Acari: Oribatida: Crotonoidea). Genus, Wroclaw

Philipp M (1997) Genetic diversity, breeding system, and population structure in Silene acaulis (Caryophyllaceae) in west Greenland. Opera Botanica 132:89-100

Polunin N (1951) The real Arctic: suggestions for its delimitation, subdivision and characterization. J Ecol 39:308-315. https://doi.org/10.2307/2257914

Potapov MB (2001) Synopses on Palaearctic Collembola: isotomidae. In: Dunger W (ed) Abhandlungen und Berichte des Naturkundemuseums. Staatlicjes Museum für Naturkunde Görlitz 73:1-603

Reid AN, Lortie CJ (2012) Cushion plants are foundation species with positive effects extending to higher trophic levels. Ecosphere 3:1-18. https://doi.org/10.1890/ES12-00106.1

Reid AM, Lamarque LJ, Lortie CJ (2010) A systematic review of the recent ecological literature on cushion plants: champions of plant facilitation. Web Ecol 10:44-49. https://doi.org/10.5194/we-10-44-2010

Sieber Y, Holderegger R, Waser NM et al (2011) Do alpine plants facilitate each other's pollination? Experiments at a small spatial scale. Acta Oecologica 37:369-374

Sklenář P (2009) Presence of cushion plants increases community diversity in the high equatorial Andes. FloraMorphology, Distribution, Functional Ecology of Plants 204:270-277

Statistica (2013) Version 12. StatSoft Inc

Sullivan GT, Ozman-Sullivan SK (2021) Alarming evidence of widespread mite extinctions in the shadows of plant, insect and vertebrate extinctions. Austral Ecol 46:163-176

Sutton JT, Hermanutz L, Jacobs JD (2006) Are frost boils important for the recruitment of arctic-alpine plants? Arct Antarct Alp Res 38:273-275

Thibaud J-M, Schulz H-J, da Gama Assalino MM (2004) Synopses on palaearctic collembola: hypogastruridae. In: Dunger W (ed) Abhandlungen und Berichte des Naturkundemuseums. Staatlicjes Museum für Naturkunde Görlitz 75:1-287

Villellas J, García MB, Morris WF (2019) Geographic location, local environment, and individual size mediate the effects of climate warming and neighbors on a benefactor plant. Oecologia 189:243-253

Walter DE, Proctor HC (1999) Mites: ecology, evolution, and behaviour. Springer

Weigmann G (2006) Hornmilben (Oribatida). Keltern, Goecke \& Evers, p 520

Zimdars B, Dunger W (1994) Synopses on Palaearctic Collembola: Tullbergiinae. In: Dunger W (ed) Abhandlungen und Berichte des Naturkundemuseums. Staatlicjes Museum für Naturkunde, Görlitz 
Zumsteg A, Bååth E, Stierli B et al (2013) Bacterial and fungal community responses to reciprocal soil transfer along a temperature and soil moisture gradient in a glacier forefield. Soil Biol Biochem 61:121-132

Publisher's Note Springer Nature remains neutral with regard to jurisdictional claims in published maps and institutional affiliations.

\section{Authors and Affiliations}

\section{Peter Ĺuptáčik ${ }^{1}$ (D) Peter Čuchta ${ }^{2}$ Patrícia Jakšová ${ }^{1}$. Dana Miklisová ${ }^{3}$ (D) Lubomír Kováč ${ }^{1}$ D . Juha M. Alatalo ${ }^{4}$ iD}

1 Institute of Biology and Ecology, Faculty of Science, Pavol Josef Šafárik University in Košice, Šrobárova 2, 04154 Košice, Slovakia

2 Biology Centre, Institute of Soil Biology, Academy of Science of the Czech Republic, 37005 České Budějovice, Czech Republic

3 Institute of Parasitology, Slovak Academy of Sciences, Hlinkova 3, 04001 Košice, Slovakia

4 Environmental Science Center, Qatar University, 2713 Doha, Qatar 